\title{
El comercio de la cultura: el caso de los pueblos amazónicos
}

Le commerce de la culture : l'exemple des sociétés amazoniennes

The commerce of culture: an example from Amazonía

Jean-Pierre Chaumeil

\section{CpenEdition}

Journals

Edición electrónica

URL: http://journals.openedition.org/bifea/2822

DOI: $10.4000 /$ bifea.2822

ISSN: 2076-5827

Editor

Institut Français d'Études Andines

Edición impresa

Fecha de publicación: 1 abril 2009

Paginación: 61-74

ISSN: 0303-7495

Referencia electrónica

Jean-Pierre Chaumeil, «El comercio de la cultura: el caso de los pueblos amazónicos », Bulletin de I'Institut français d'études andines [En línea], 38 (1) | 2009, Publicado el 01 octubre 2009, consultado el 17 noviembre 2020. URL : http://journals.openedition.org/bifea/2822 ; DOI : https://doi.org/10.4000/ bifea.2822

\section{(c)}

Les contenus du Bulletin de l'Institut français d'études andines sont mis à disposition selon les termes de la licence Creative Commons Attribution - Pas d'Utilisation Commerciale - Pas de Modification 4.0 International. 


\title{
El comercio de la cultura: el caso de los pueblos amazónicos
}

\author{
Jean-Pierre Chaumeil
}

\begin{abstract}
Resumen
En este breve ensayo el autor nos brinda una reflexión sobre el hecho turístico y algunas de sus implicaciones locales, en particular, lo referente a su impacto entre las poblaciones indígenas amazónicas. Procura acercarse al tema más general de la cultura como producto de consumo, y su puesta en escena como nueva forma de relación/dominación social. También reflexiona sobre el proceso de patrimonialización —o «museificación»— de la cultura y sus efectos de «puesta en archivos» o de «puesta en memoria», al igual que las propias nociones de «propiedad» y«patrimonio», y su aplicación/adecuación en el contexto de las culturas amazónicas.
\end{abstract}

Palabras clave: Amazonía, turismo, patrimonialización, cultura y consumo, Convención de la Unesco sobre el Patrimonio Cultural Inmaterial

\section{Le commerce de la culture : l'exemple des sociétés amazoniennes}

\section{Résumé}

Dans ce court essai l'auteur se propose de mener une réflexion sur le fait touristique et ses implications locales, en particulier parmi les populations indigènes d'Amazonie, mais aussi sur le thème plus général de la culture comme produit de consommation, et ses différentes mises en scène comme nouvelle forme de relation/domination sociale. Il s'interroge dans un second temps sur le processus de patrimonialisation - ou de muséification - de la culture et ses effets de «mise en archives » ou de « mise en mémoire », ainsi que sur les notions mêmes de " propriété » et de « patrimoine », et leur possible application/adéquation dans le contexte des cultures amazoniennes.

Mots clés: Amazonie, tourisme, patrimonialisation, culture et consommation, Convention de l'Unesco sur le Patrimoine Culturel Immatériel 


\title{
The commerce of culture: an example from Amazonía
}

\begin{abstract}
In this essay the author offers a reflection on tourism and some of its local effects, especially on the indigenous peoples of Amazonia, and on the more general subject of culture as a product of consumption and its exhibition as a new form of social relation. He engages himself also in a reflection on the actual process of «patrimonialization» or «museification» of culture and on notions of «property» and «patrimony», and their the adequacy of their application in the context of Amazonlan cultures.
\end{abstract}

Key words: Amazonia, tourism, patrimonialization, culture and consumption, Convention of the Unesco on Immaterial Cultural Patrimony

Los temas referidos a la exhibición y al comercio de las culturas, así como también su «patrimonialización»o su puesta en museo, se han vuelto fundamentales en el análisis antropológico de hoy por varios motivos; empezando por el fuerte crecimiento de la industria turística en el mundo, una de las actividades globalizadas más lucrativas del momento. Existen poblaciones en varias partes del mundo que han vivido buena parte, o incluso toda su vida, como objetos turísticos. Por otro lado, dichos temas suscitaron un vivo interés en el marco de las reflexiones sobre los museos y la nueva pasión occidental por el «arte primitivo» o étnico (Derlon \& Jeudy-Ballini, 2008), incluso con referencias a la Convención de la UNESCO — ratificada en 2003- sobre la salvaguardia del Patrimonio Cultural Inmaterial (PCI), que suscribieron más de 100 países, y que implica repensar la noción misma de patrimonio.

\section{LA INDUSTRIA TURÍSTICA: ¿UNA NUEVA BONANZA EN LA AMAZONÍA?}

En un artículo reciente, G. Ochoa (2008a) planteaba la cuestión del turismo como posible nueva bonanza en la Amazonía, encontrándose esta actividad, como se ha dicho, entre las de mayor crecimiento en el mundo1. La «bonanza del turismo» es, en efecto, la expresión que utilizan algunos indígenas para referirse al fenómeno actual de incremento de la actividad turística (Ochoa, 2008a: 45). Esta misma expresión de bonanza ha sido, a menudo, utilizada en el pasado en relación a los diferentes booms que han sacudido la región, como los del caucho, el petróleo, el oro o la coca. Salvo que hoy la actividad turística no se presenta solamente como una nueva «alternativa de desarrollo», dinamizadora o generadora de empleo (a la manera del petróleo o la coca), sino que explota los nuevos estereotipos de la protección ambiental y la figura del indígena como «nativo ecológico», dos clichés que forman parte de la construcción del imaginario occidental sobre la selva.

1 La Organización Mundial del Turismo ha estimado que la cifra de turistas internacionales viajando por el mundo en el año 2007 sobrepasó los 900 millones (Ochoa, 2008c: 9). El mismo año, la Organización del Tratado de Cooperación Amazónico (OTCA) lanzó la iniciativa «Año del Destino Amazonía 2009». «La iniciativa incluye una intensa campaña publicitaria y la realización de múltiples eventos y actividades para fortalecer la imagen de la Amazonía en el mercado turístico mundial, para aumentar el número de visitantes, las rentas nacionales y mejorar la calidad de vida de la población local» (2008c: 10, nota 1). 
La importación y la representación pública de ceremonias, bailes y fiestas procedentes de las más lejanas regiones del mundo tienen una larga tradición en la historia del colonialismo (Fiorini \& Ball, 2006). Los primeros shows (espectáculos, representaciones) de los indígenas de América en el Viejo Mundo se remontan a los principios del siglo XVI (Seiler-Baldinger, 1988). Recordaremos al respecto, la famosa «Fiesta Tupinamba» celebrada en Rouen, en 1550, ante el rey de Francia, Henri II, y la reina Catherine de Medicis, celebración redescubierta tres siglos más tarde por Ferdinand Denis en un célebre estudio (Denis, 1850). La participación de amerindios en desfiles y conmemoraciones en las cortes de los reyes de Europa ha sido un hecho relativamente corriente a lo largo del siglo XVI. Se trataba, en general, de prisioneros de guerra comprados a menudo como esclavos para ser exhibidos después en Europa (Francia, Portugal, España o Inglaterra) como curiosidades humanas (Perronne-Moisés, 2008: 56). En el caso de la celebración de Rouen, sin embargo, se trataba más bien, según Perronne-Moisés (2008), de celebrar la alianza política entre los franceses y los tupinamba, y no tanto de poner en escena la «realidad» de su modo de vida para un público ávido de exotismo (algo cierto también). Aunque estas actuaciones no son exactamente comparables con la actual mercantilización de la cultura dentro del fenómeno turístico, no son tampoco del todo ajenas a dicho proceso que, de cierta manera, prefiguran (figs. 1-2).

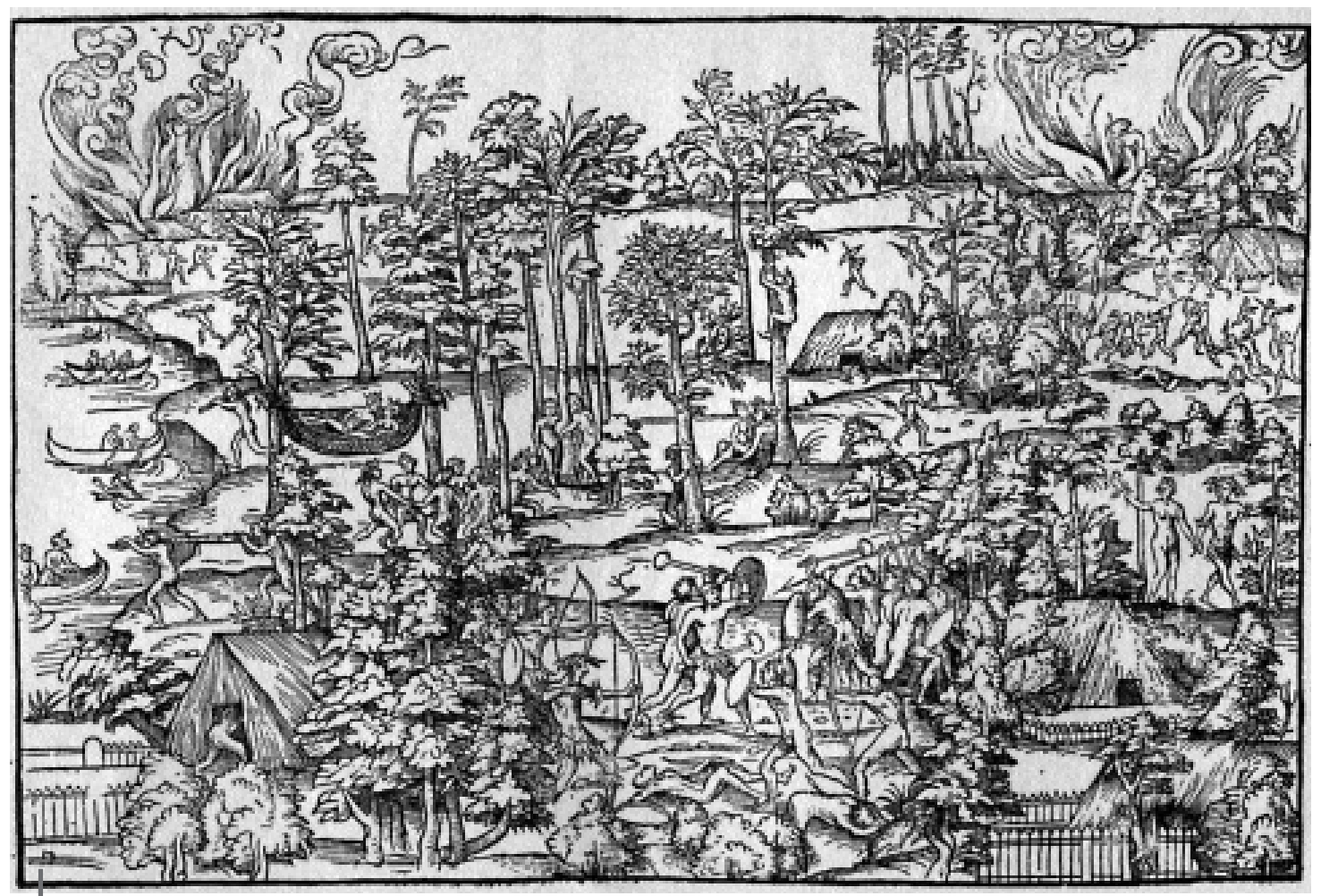

Figura 1 - Lámina que ilustra la «fiesta brasilera» celebrada en Rouen para el rey Henry II (1550) Fuente: Carneiro da Cunha (1992: 20) 


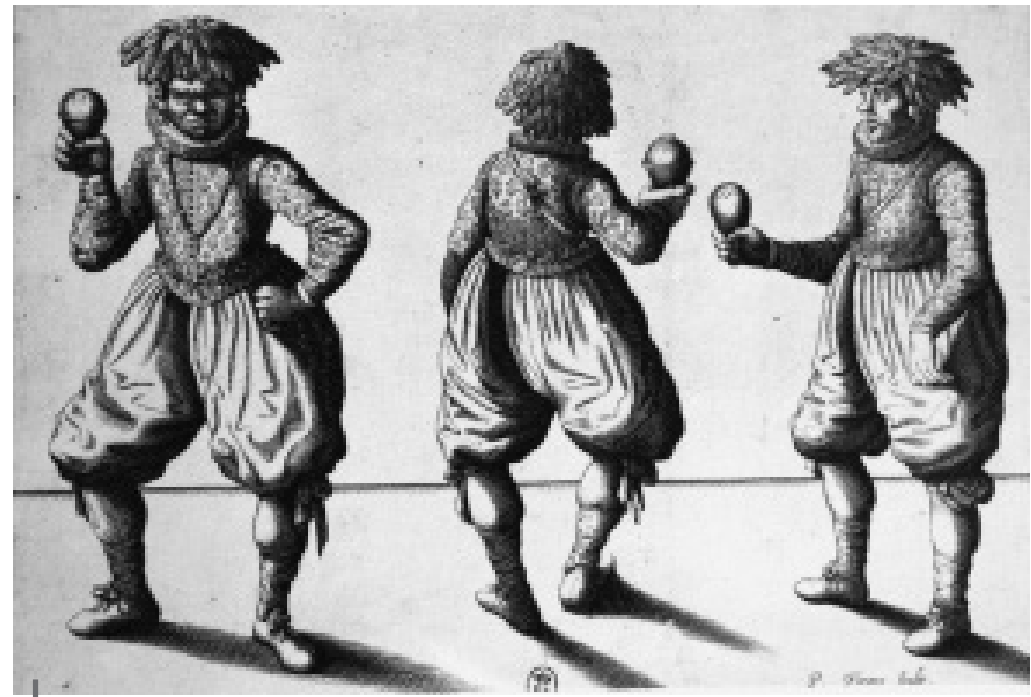

Figura 2 - Danza con maracas de los tupinamba en la corte de Francia (1650) Fuente: Carneiro da Cunha (1992: 13)

A lo largo del siglo XVIII y sobre todo del XIX, era costumbre de los viajeros (que quizás podríamos calificar de «primeros turistas») pedir a los indígenas muestras de sus fiestas y bailes, más exactamente, a los misioneros y colonos que les hacían ejecutar danzas para ellos. Imaginada o construida como un espacio vacío, salvaje y exótico, la Amazonía empezó a venderse como un producto de consumo (Rodríguez \& Aponte, 2008).

Hoy en día, se sigue comprando rituales amazónicos a pedido. Ese ha sido el caso reciente respecto al baile de las máscaras de los waujá del Xingu (Brasil), ejecutado en Francia con ocasión de la inauguración, en el año 2005, de una colección de objetos amazónicos en el Museo du quai Branly (Fiorini \& Ball, 2006). Se puede incluso adelantar que la venta (comercialización) de rituales y objetos rituales caracteriza, desde hace diez años, las formas de relación entre indígenas y no indígenas — Barcelos Neto (2006); y sobre la circulación y el valor del dinero en las culturas amazónicas, ver en particular Gordon (2009) a propósito de los kayapo-xikrin-.

Se puede estimar que las primeras empresas turísticas en la Amazonía peruana empezaron, de manera sistemática, hacia los años 1960, en particular en la zona de Iquitos — cuatro siglos después de la famosa «fiesta tupinamba» celebrada en Rouen-. Sin embargo, recién a partir de la década de 1980, aparecieron los primeros estudios de caso sobre el tema en la zona que nos interesa (Baca, 1981; Chaumeil, 1984; Seiler-Baldinger, 1988).

La mayoría de los trabajos contrasta el turismo convencional de empresa o de masa (que depende de unas cuantas grandes empresas multinacionales) con un turismo alternativo o «sostenible» (durable) de tipo tradicional (endógeno, etno-ecoturismo, etc.) que involucra directamente a las poblaciones locales (a nivel individual o comunal), quienes deciden en principio la manera de «dar a ver» (valorar) su patrimonio cultural a través de diferentes tipos de representación, producción artesanal o museos locales (etno-ecomuseos). Se podría quizás ver el turismo «místico» — como el caso de la comercialización del chamanismo entre los shipibo-conibo (Dziubinska, 2008) o de la industria de la ayahuasca en lquitoscomo un producto derivado del turismo alternativo, pero con lógica propia. Desde los 
años 1970-1980, la industria turística ha tratado de tomar un nuevo rumbo en conformidad con el discurso global hacia mayor participación local y preservación ambiental. Existen varios estudios recientes sobre el tema, que tratan de mostrar las bondades de esta última forma de turismo para la preservación o puesta en valor del patrimonio cultural indígena y su capacidad creativa — véase, por ejemplo, Stronza, 2001; Pastor Alfonso, 2007; Taylor, 2008; Ochoa, 2008d. Para un buen análisis del contexto de despegue del ecoturismo en la Amazonía, consultar Grisales, 2008: 209-220-. Algunos trabajos presentan, a veces, al turismo de aldea como si fuera la actividad generadora de ingresos económicos, mejor adaptada al modo de vida indígena y la más respetuosa del entorno. Stronza (2001) analiza el turismo alternativo como una forma de relaciones o contactos interculturales al explorar no solamente cómo esta actividad puede proporcionar beneficios sociales, económicos y medioambientales para las comunidades locales; sino también en qué medida puede constituir una experiencia transformadora para los propios turistas. Según la autora, todo acercamiento «holista» del turismo digno de este nombre tendría que tomar en cuenta los dos términos de la relación y no, como se viene realizando, el único punto de vista de los actores locales. Volviendo a la Amazonía, el libro recientemente editado por G. Ochoa sobre el turismo en esta región (2008b), por interesante que sean las contribuciones, no ofrece mucho material de reflexión crítica al presentar textos y experiencias de casos redactados, en su mayoría, por asesores y profesionales del turismo (a falta de un acercamiento sociológico o antropológico). La única contribución del libro a cargo de un líder indígena, ticuna en este caso, muestra de manera interesante cómo la implementación de un programa de turismo en su aldea resultó, en realidad, ser una iniciativa suya, después del rechazo, algunos años antes, de dicho programa por la comunidad. De manera general, existen pocos estudios precisos sobre el nivel real de participación de los comuneros de las aldeas en la actividad turística.

De todas formas, se puede hablar en términos generales de cierta institucionalización del turismo a nivel local por parte de los indígenas, no solo en las comunidades sino a nivel de asociaciones. Por ejemplo, en Colombia, la Asociación de Cabildos Indígenas del Trapecio Amazónico (ACITAM) se encuentra debatiendo su Ley de Turismo Indígena y se dispone a presentar un proyecto que busca la capacitación de líderes (los famosos cursos de capacitación a cargo de las ONG) en unas 20 comunidades asociadas (Ochoa, 2008b: 65). Esta idea de «capacitar» a los indígenas para el turismo cuestiona los anteriores cursos de capacitación sobre el manejo forestal o la piscigranja, por citar solo algunos, con los resultados que conocemos.

Sin embargo, uno se puede preguntar sobre este tipo de «normatización» o reglamentación a todo precio de las prácticas y los saberes —como ocurrió en otros campos, por ejemplo, en el caso del chamanismo con los famosos sindicatos o asociaciones de chamanes indígenas, dotados de una personalidad jurídica del derecho privado-. En efecto, tales asociaciones han juzgado necesario definir normas y criterios que configuran a un «buen chamán», como eventual medida preventiva contra los «actos de brujería», que tienden a multiplicarse en las comunidades en estos últimos años (Truffin, 2006: 339). Inútil es precisar que semejantes medidas, muchas veces, no han tenido los resultados esperados. No obstante, encontramos cada vez con más frecuencia una verdadera «obsesión» normativa o legislativa en el seno de las organizaciones indígenas. J. Jackson (1995a; 1995b) analiza también el interesante caso de la «escuela chamánica» entre los tucano del Vaupés colombiano, iniciativa financiada por el Ministerio de la Salud y la cooperación holandesa. Este proyecto de escuela chamánica fue promovido en 1983 por un antropólogo encargado de los programas de salud en la región, con el propósito de salvaguardar la medicina indígena al asegurar la transmisión del saber chamánico en forma colectiva, sobre el modelo de la enseñanza escolar. Esta experiencia terminó, como se podía preveer, en un fracaso rotundo por varios motivos 
expuestos por Jackson (1995b: 313-318). Entre los principales motivos resalta una cierta visión idealizada, hasta romántica, del chamanismo amerindio al imaginarlo como si fuera un cuerpo de conocimientos fijos, normativos, orientados únicamente hacia las curaciones, cuando se trata en realidad, como bien se sabe, de un sistema social complejo y dinámico, que presenta múltiples facetas improvisadas (no codificadas) como también formas de agresión interpersonales.

Esta visión expurgada y codificada del chamanismo es, por supuesto, una invención nuestra que encaja con el esfuerzo de querer reglamentar o inventoriar a todo precio los conocimientos y las prácticas indígenas. El caso de la escuela chamánica de los tucano, descrito arriba, constituye quizás el perfecto ejemplo de lo que no conviene hacer en relación a proyectos de salud en contextos interculturales (Jackson, 1995b: 313).

¿Hasta qué punto una ley o un conjunto de leyes puede controlar o impedir el movimiento de las prácticas y de las ideas? ¿Transformar por leyes la cultura en propiedad no equivaldría finalmente a reducir la libre circulación de los saberes, espacios o identidades? ¿Cuál sería entonces el futuro del dominio público? (Brown, 2003a). La cuestión central planteada aquí concierne al problema de la adaptación o de la articulación de tradiciones y ontologías amazónicas descritas por los antropólogos en términos reticulares, flexibles y relacionales a un marco normativo rígido y formalizado (Truffin, 2006; Gutjahr, 2008). Este carácter reticular y lábil de las cosmologías indígenas, lejos de ser (como se ha dicho a menudo) una mera sobrevivencia del pasado (Pastor Alfonso, 2007), parece al contrario de gran originalidad y modernidad en el mundo globalizado y interconectado de hoy.

Por otro lado, los estudios muestran cómo el argumento de la autenticidad, de lo «auténtico», muy ligado a la actividad turística por cierto, lleva a la definición de lo que sería, según los propios términos de los interesados, el «verdadero» indígena o el «nativo de verdad», como lo mostró A. Chaparro en el caso de los yagua (Chaparro, 2008). Los «nativos de verdad», según la expresión de los yagua, serían los que saben realizar la puesta en escena, los bailes y hablar el idioma frente al turista, y que por consiguiente tratan de monopolizar los ingresos a nombre de la comunidad, suscitando inevitables tensiones entre los comuneros. El criterio de la «autenticidad» Ilevaría a esta situación absurda del uso del idioma no para comunicar, sino para «venderse» mejor, como una marca registrada en suma (Chaparro, 2008: 130-131).

Aquí el argumento de la autenticidad del «verdadero indígena» alcanza mucha significación, e indica finalmente que la puesta en escena del Otro — que se la llama bajo el nombre de turismo alternativo o de otra manera- no parece haber cambiado mucho en cinco siglos: desde la famosa fiesta tupinamba de 1550 siempre es el salvaje o se reproducen los clichés sobre el salvaje. Si el término cambió, la naturaleza de la relación permanece. De otro lado, y referiéndose a estos mismos indígenas, L. Gallego señaló la ambigüedad de la figura del turista entre lós yagua de la comunidad La Libertad, en la Amazonía colombiana, al percibir a los turistas como depredadores y chupadores de sangre, lo que no les impide acoger a dichos turistas con b́ombos y bailes, como suele hacerse en toda puesta en escena turística digna de este nombre. Desde su punto de vista, en efecto, el frenesí de los turistas para adquirir artefactos indígenas esconde el deseo depredador de desposeer a los yagua, de «chupar» su sangre y sus pensamientos (Gallego, 2004). A propósito de los shipibo-conibo, Dziubinska pone en paralelo la figura del Otro, nawa, propia del sistema sociocosmológico de este pueblo con la figura de los turistas, como imagen prototípica del extranjero depredador (Dziubinska, 2008).

Este mismo criterio de lo auténtico se encuentra también en la producción artesanal. Es así que los waujá, de los que hemos hablado antes, contrastan los objetos realizados en contexto ritual, llamados «verdaderos» en su lengua, de los destinados al turismo llamados 
«paraguay», término que se aplica a los objetos falsos o de muy mala calidad según sus propios criterios (Barcelos Neto, 2006).

Por otro lado, la creación de museos locales asociados a proyectos turísticos plantea la cuestión de cómo una cultura y qué rasgo de su patrimonio decide mostrar, con el peligro que los elementos escogidos se transformen a su vez, como suele pasar, en nuevos estereotipos de la cultura en cuestión. Tenemos, por ejemplo, el caso del museo ticuna «Magüta» (Centro de Documentaçâo e Pesquisa de Alto Solimoês) que se encuentra en la ciudad brasilera de Benjamin-Constant (río Yavari), fronteriza con Perú, y que ha sido conceptualizado y administrado por los propios ticuna. Este centro decidió orientar su presentación sobre el ritual de la «pelazón» (iniciación feminina espectacular, en el que se arranca, entre otras cosas, el cabello de las novicias) a partir de una serie de fotos antiguas, presentadas sobre carteles, que fueron tomadas hace más de 50 años por viajeros y antropólogos. Como si esas fotos fueran la garantía o la prueba de «autenticidad» del ritual. Es así como, poco a poco, esta fiesta - y sus artefactos rituales asociados (máscaras sobre todo) - se han transformado en marca emblemática y casi comercial de los ticuna, quienes son identificados $-\mathrm{y}$ hasta cierto punto se identifican ellos mismos - a través de esta imagen. Se podría seguramente observar lo mismo con la imagen que figura en todos los prospectos turísticos de los yagua como «hombres-cerbatanas» (Chaumeil, 1984) o de los jívaro como «cortadores de cabezas», a pesar que los primeros no fabrican más cerbatanas (salvo muy malas copias para los turistas) y que los segundos cesaron de cortar cabezas —si es que alguna vez lo hicieron-. Sabemos que los estereotipos tienen larga vida. Entonces, vemos hasta qué punto la «cultura» es, en primer lugar, un constructo de las interacciones con el mundo exterior (fig. 3).

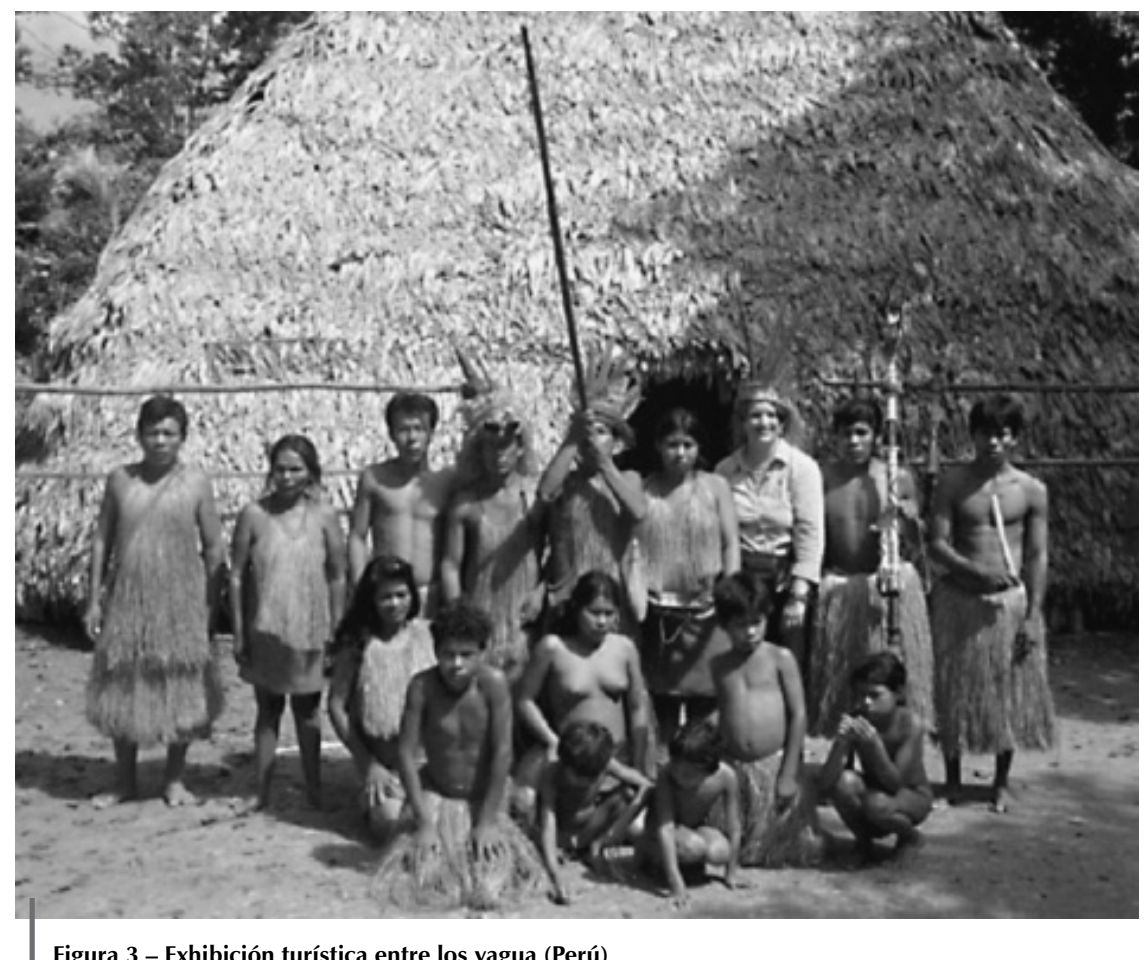

Figura 3 - Exhibición turística entre los yagua (Perú) 
Si bien el crecimiento del fenómeno turístico está relacionado y ha influido sobre el actual proceso de reificación y patrimonialización de la cultura de los pueblos indígenas, no es el único ni el principal factor de formalización de tal proceso. Los numerosos esfuerzos indígenas para definir su patrimonio, de una manera muy formal y burocrática, son también una respuesta a la crisis mundial de la propiedad intelectual, así como a la mundialización de la información (Brown, 1998; 2003a; 2003b). La Convención de la Unesco sobre el Patrimonio Cultural Inmaterial (PCl) puede ser analizada, desde esta perspectiva, como una consecuencia de la preocupación sobre los efectos culturales de la llamada globalización.

\section{LA CONSTRUCCIÓN DE UN PATRIMONIO}

Con el reforzamiento de los derechos indígenas, paralelamente al incremento de la industria turística, las preocupaciones referentes al tema de la propiedad intelectual y los cambios tanto en las políticas públicas como en el sector privado (especialmente con la presencia de las compañías petroleras), surgió entonces la necesidad de definir nuevos conceptos como los de «propiedad indígena» o «patrimonio cultural», que podrían servir de base para elaborar normas de uso y de protección en favor de los conocimientos y artefactos producidos por los propios pueblos indígenas.

Esta cuestión importante acerca de las modalidades de almacenamiento, protección, codificación, regulación y transmisión de los saberes calificados de «tradicionales» se realizó utilizando el lenguaje occidental de la propiedad intelectual: los interesados no vacilan en afirmar desde entonces sus derechos de autor sobre cantos, mitos y bailes, imponiendo su nombre o el nombre de su grupo como marca registrada (trademark).

Este proceso de patrimonialización implicó un cambio mayor en las concepciones indígenas. Presupone, en particular, un trabajo previo de «objetivación» del saber y de la cultura (de Vienne \& Allard, 2005: 129). Como lo plantea J. Jackson en el caso de los tucano, el problema para los indígenas no es tanto aceptar o rechazar la sociedad occidental, sino más bien inventar o negociar cuáles serían las formas culturales propias que desean guardar y dar a ver. Es un proceso que implica un diálogo interno con ellos mismos, al igual que un acercamiento sobre la manera de cómo estudiar o investigar su propia cultura (Jackson, 1995b). Desde una perspectiva cultural que valora lo que viene de afuera - donde todo o casi todo se define y se piensa a partir de las interacciones con el exterior y no a partir de sí mismo-, se debe ahora pensar la cultura como algo que sería cerrado, intrínseco, autónomo, que solo se podría imaginar a partir de sí mismo, con un contenido preciso que se puede incluso comprar, vender o perder, que tiene un valor político pero en el sentido estrecho del término: un patrimonio $-\mathrm{y}$ no más como relación social- cuando se conoce el rol crucial devuelto a la alteridad en los sistemas sociocosmológicos amerindios (Gallois, 2006: 78). Ocurre con frecuencia, por ejemplo, que un grupo indígena sea acusado de no tener cultura por el hecho de no estar en condición - por un motivo u otro (falta de alimento, de conocimiento, etc.) — de poder organizar sus bailes: no tiene, entonces, nada visible que mostrar al foráneo (de Vienne \& Allard, 2005: 138). Inútil es precisar que estas concepciones son completamente ajenas a la mayoría de las culturas amazónicas, mucho más abiertas a la adquisición y la creación (transformación) permanente, que a la transmisión patrimonial. El cambio efectuado aquí es una modificación radical en el modo de concebir la «cultura», independientemente de las formas culturales en sí que son sometidas, por definición, a continuos cambios.

La noción misma de propiedad indígena no se aplicaría tanto a la posesión de un objeto (que sea material o inmaterial), sino más bien a la relación entre personas a propósito de 
un objeto: puede tratarse de una relación de fuerzas o de intercambio, de protección o de predación (de Vienne \& Allard, 2005). En el chamanismo, por ejemplo, el control sobre los espíritus o la posesión de un espíritu familiar depende de la relación de fuerzas entre chamanes; sabiendo que un chamán más fuerte puede quitarle conocimientos y armas a su rival. Últimamente se ha desarrollado una reflexión sobre las nociones de control, de posesión, de maestría, en el caso de las poblaciones indígenas de la Amazonía, a partir de la figura ampliamente difundida en estas regiones de los «dueños» de la selva, quienes controlan y protegen la fauna y la flora contra la depredación de los humanos 2 . Resalta de la reflexión que dichas nociones no se limitan a una simple relación de dominio o de propiedad, pues no implican el uso exclusivo de un objeto, de una cosa o de cualquier bien material o inmaterial. En la Amazonía indígena no parece existir, salvo rara excepción, propiedad privada sobre los recursos naturales (Fausto, 2008). Entre los yagua, por ejemplo, la noción de propiedad se expresa utilizando el sustantivo hamwo, que designa el principio vital de los seres animados, los dueños de los grandes rituales y los espíritus de la selva así como los líderes o dueños de maloca [casa grande] (Chaumeil, 2005). Todo ocurre como si se pudiera pensar la propiedad fuera de la posesión exclusiva de bienes (Fausto, 2008).

De otro lado, los mitos o los dibujos no son de un individuo en particular, sino que pertenecen al saber común, compartido: hay contadores o dibujantes mejores que otros, pero no existen propietarios de mitos o de motivos iconográficos3. Con este proceso de inventorio y registro de su patrimonio cultural emprendido por los pueblos indígenas - tarea que podría calificarse de etnomuseográfica4-, este saber compartido, común a la mayoría, tiende a esencializarse, fijarse, privatizarse, descontextualizarse. Es una tendencia observada en muchos sitios cuando la versión grabada y transcrita de un mito o de un canto se vuelve una norma que no puede sufrir la menor variación —imponiéndose como la versión canónica-, incluso se vuelve propiedad exclusiva de una persona o de un grupo que puede hasta determinar su precio en dinero. G. Taylor (1996: 20) mostró —a propósito de la tradición quechua - cómo, ante el riesgo de la desaparición de su tradición oral, un individuo o un grupo puede establecer un texto de referencia a partir de las múltiples variantes de los relatos tradicionales, como el famoso caso del manuscrito de Huarochirí que llegó a tener, como bien se sabe, un valor de documento absoluto. Por otro lado, el registro de estos bienes culturales tiene un supuesto segundo propósito: regular su eventual empleo por parte de los foráneos, antropólogos incluidos (de Vienne \& Allard, 2005).

\section{LA CONVENCIÓN DE LA UNESCO}

En el año 2003 se adoptó en la UNESCO la Convención para la Salvaguardia del Patrimonio Cultural Inmaterial (ratificada en más de 100 países), que invita a repensar

2 Nos referimos al seminario Agentivité organizado por Aurore Monod y Valentina Vapnarsky en el Centre EREA del Laboratoire d'Ethnologie et de Sociologie Comparative CNRS (Université Paris-Ouest, Nanterre La Défense).

3 En un texto reciente, Hugh-Jones ha vuelto sobre el tema al argumentar que los tucano tendrían una tendencia «natural» para objetivar su cultura y entenderla como una forma de propiedad (Hugh-Jones, 2009). Esta característica — no tan común en las tierras bajas - estaría, según el autor, ligada a un rasgo particular de la estructura social tucano, como la presencia de grupos patrilineares cuya identidad depende del control de bienes materiales e inmateriales, pero también del alto estatus otorgado a los kumu (chamanes-sacerdotes) cuya posición descansa sobre el dominio de un saber esotérico (Hugh-Jones, 2009).

4 Véase el caso documentado por A.-G. Bilhaut de la creación de la casa de los archivos de la memoria entre los zapara del Ecuador (Bilhaut, 2007). Lo interesante en el caso zapara es que los documentos registrados no son utilizados, sino archivados y conservados para constituir huellas o rastros de la existencia de algo. Al comparar los kayapó del Brasil con los kanak de Neo-Caledonia, E. Gutjahr (2008) analizó la manera en que el registro de la cultura ha sido o no recuperado en la cadena de transmisión de conocimientos de estas dos sociedades. 
la noción de patrimonio y al mismo tiempo va reforzando, como veremos, el proceso de institucionalización (invención) de la cultura5.

Esta noción de Patrimonio Cultural Inmaterial ( $\mathrm{PCl}$ ) generó una pequeña revolución conceptual, porque implica colocar al objeto (material) en segundo plano, para privilegiar la práctica así como el punto de vista de los interesados. Estos últimos se ven investidos de una nueva legitimidad al ser los únicos que pueden decidir la «autenticidad» de lo que pertenece o no a su $\mathrm{PCl}$. Recordemos que las visiones anteriores del patrimonio privilegiaron sobre todo los aspectos materiales de las cosas. En el nuevo concepto, se pueden incluir en el PCI las tradiciones y expresiones orales, bailes y temas musicales, y los rituales y prácticas sociales.

$\mathrm{El} \mathrm{PCl}$ se define de la siguiente manera:

«Las prácticas, representaciones, expresiones, conocimientos, así como los instrumentos, objetos, artefactos y espacios culturales asociados, que las comunidades, los grupos y eventualmente los individuos reconocen como parte de su patrimonio cultural. Transmitido de generación en generación, este patrimonio cultural inmaterial es recreado de manera permanente por las comunidades y grupos en función de su medio, de su interacción con el entorno y de su historia. Les otorga un sentimiento de identidad y de continuidad, contribuyendo así a promover el respeto de la diversidad cultural y de la creatividad humana» (Hottin ed., 2008: 15).

Se trata de una definición no estática que focaliza la transmisión y creación permanente, lo que a primera vista no contradice las concepciones indígenas. La Convención quiere ser una herramienta para evitar la desaparición de los bienes del patrimonio de la humanidad, hoy amenazados. Se creó para ello un fondo y varios grupos de la Amazonía están recopilando su lista en una lógica o dinámica patrimonial; es decir, en una perspectiva totalmente nueva para ellos que moviliza además, en forma creciente, nuevos recursos: la escritura y la producción de documentos escritos (sobre este tema ver Bilhaut, 2007; Gutjahr, 2008)6.

Sabemos que buena parte de la producción (material e inmaterial) indígena tiene como característica su condición efímera y el compartido de ser —en muchos casos- destruida o transformada una vez acabado el ritual o a la muerte de la persona que la usaba —véase Münzel (2000-2001); y sobre la poca durabilidad y el destino de los artefactos rituales en los Andes y la Amazonía, véase el estudio comparativo de Barcelos Neto (2008)—. Quizás, en este caso, sería más conveniente hablar de transformaciones en vez de destrucción, teniendo en cuenta que dichos objetos, una vez utilizados o desactivados, pueden cambiar de significado o adquirir nuevas significaciones más allá de su aniquilación física (N. Pétesch, comunicación personal).

Se podría decir lo mismo de buena parte de la producción oral (muchos cantos rituales se recomponen en cada generación, o incluso en cada ritual). Describiendo los objetos del archipiélago Bismarck (en Melanesia), el escritor surrealista André Breton decía que no hubiera tenido que verlos ya que hubieran sido destruidos, al final del ritual, en su cultura de origen (Derlon \& Jeudy-Ballini, 2008: 11). Procediendo de un pensamiento en el que no existe belleza ni tampoco objetos que no sean efímeros, su destrucción o transformación

5 Para más información sobre la historia de la Convención y la evolución de la noción de patrimonio, así como la producción de documentos referente a las políticas de protección del PCI, véase Gallois (2006: 16, 82-88).

6 A.-G. Bilhaut y S. Macedo organizarán en el marco del $53^{\circ}$ Congreso Internacional de Americanistas — que tendrá lugar en la ciudad de México en julio 2009- un simposio titulado «Tradición, patrimonialización y escritura», que reflexiona precisamente sobre el rol fundamental de la escritura en las acciones de protección de las tradiciones orales, como un modo privilegiado de transmisión de estas tradiciones basadas en la oralidad. 
obliga a replicarles cada vez: así los objetos rituales aparecen y desaparecen para nacer de nuevo. Recolectados y conservados en museos o colecciones privadas, ciertos objetos indígenas —entre los más antiguos- alcanzan hoy cifras astronómicas en el mercado del arte primitivo (Derlon \& Jeudy-Ballini, 2008: 11).

Ahora, si nos ubicamos más allá del objeto (en el marco del PCI), existe una transmisión de los saberes entre las personas (cantos, motivos iconográficos, etc.), pero, como lo hemos señalado, gran parte de esta transmisión — quizás la parte esencial— no depende de un cuerpo de conocimientos dado, establecido para siempre - excepto en algunos casos, véase Hugh-Jones (2009) —, sino de la experiencia individual o colectiva. Es así que las prácticas, como los conocimientos y las identidades, deben construirse, deshacerse, adquirirse e inventarse continuamente para ser efectivos en dichas tradiciones. Reflexionando sobre este aspecto fugitivo del arte indígena sudamericano y las políticas de conservación, Münzel escribía:

«Nuestros esfuerzos etnográficos de captar estos momentos fugitivos, sea por el almacenamiento de las máscaras, sea por la colección de los mitos y la grabación de las canciones, son como esfuerzos para luchar contra la fugitividad, lo pasajero, lo efímero del arte indígena. Queremos conservar algo que no fue producido para la conservación. Los objetos que se guardan en los museos están arrancados de su relación viva. Las escenas artificialmente reconstruidas en las salas de exposición son escenas muertas. Esta lucha contra un elemento esencial del arte indígena —el de no querer conservarse- es necesario y hoy en día cuenta también con el apoyo de muchos indígenas, ellos mismos se aplican en conservar por escrito sus mitos y poesías, o en museos su artesanía. Al mismo tiempo, es también una lucha contra algo muy profundo en las culturas selváticas amerindias: contra su negación de la estabilidad de lo que permanece siempre» (Münzel, 2000-2001: 159).

A modo de conclusión, cabe preguntarse ipara quién y para qué se redactó esta Convención para la Salvaguardia del Patrimonio Cultural Inmaterial? Si consideramos, en efecto, el documento de referencia, se debe, antes que nada, «respetar y actuar de acuerdo a las teorías y concepciones ontológicas de los interesados» (en este caso, los indígenas amazónicos). Por otro lado, la recopilación tendría que ir más allá de la realización de unos inventarios o listas establecidas - muchas veces fuera de contexto- por los famosos «expertos» en cultura, formados en los cursos de capacitación. Tampoco queremos decir con este argumento que los indígenas no serían capaces de realizar tales inventarios, sino que el modo de efectuarlos sigue un patrón formal y burocrático que excluye (a menudo) la historia, las trayectorias y las relaciones de los objetos patrimonializados con la dinámica ligada a su transmisión. D. Gallois presentó una discusión sobre las medidas adecuadas, según su criterio, para asegurar la salvaguarda del PCl y que habría que contemplar si se quiere mantener vivas las tradiciones culturales de los pueblos (Gallois, 2006).

En el caso de la Amazonía, la aplicación de esta Convención ofrece, sin duda, nuevas posibilidades para los interesados (en el campo del etno-ecoturismo o de la producción de artesanía, por ejemplo) pero también muchas limitaciones, en particular sobre la manera de entender las formas indígenas de producción de conocimiento y de artefactos que no se reduzcan a simples objetos de derecho o de gestión contable. Si existiera un espacio patrimonial indígena en la Amazonía, sería el de la alteridad y de la transformación, nociones no tan fáciles de traducir y registrar en un inventorio formal de bienes culturales, como lo apunta Brown (2003b). Ello muestra toda la dificultad en la aplicación del PCI para el caso de sociedades y culturas amazónicas, dadas las condiciones específicas en que producen y transmiten (heredan) sus conocimientos y artefactos (Gallois, 2006). Ahora quedan dos preguntas para esas sociedades itendrán otra alternativa, aparte de la de 
plegarse al movimiento general y participar de esta formalización planetaria de la cultura? ¿Tendrán otra opción que no sea la puesta en escena de su cultura a través del turismo? Autores como Kurin (2003) piensan que, de cualquier modo, la Convención representa un mal menor como herramienta adicional, susceptible de participar en la valoración de las culturas del mundo (el derecho a la cultura en tanto derecho del hombre) con el riesgo, sin embargo, de dejar ahí su alma. Son interrogantes y cuestiones que suscitan y suscitarán probablemente muchos debates entre los propios pueblos indígenas y que, en todo caso, preocupará mucho a la antropología en los años que vienen.

\section{Agradecimientos}

Quisiera agradecer a los participantes del coloquio «Perspectivas en antropología amazónica» que se celebró con ocasión de los 60 años del IFEA, así como a los dos evaluadores de este artículo (uno de ellos es Michael Brown), a Nathalie Pétesch, a Alex Surrallès (por los desacuerdos productivos) y a Germán Ochoa del Instituto IMANI, en Leticia, por los valiosos comentarios y sugerencias que permitieron completar y mejorar la versión inicial de este texto.

\section{Referencias citadas}

BACA, A., 1981 - El turismo y las poblaciones nativas; Iquitos: ORDELORETO (documento mimeógrafo).

BARCELOS NETO, A., 2006 - Des villages indigènes aux musées d'anthropologie. De la propriété et la vente des objets rituels amazoniens. Gradhiva, 4: 86-95.

BARCELOS NETO, A., 2008 - Choses (in)visibles et (im)périssables. Temporalité et matérialité des objets rituels dans les Andes et en Amazonie. Gradhiva, 8: 112-129.

BILHAUT, A.-G., 2007 - Le réveil de l'immatériel. La production onirique du patrimoine des Indiens Zapara; Nanterre: Universidad París X. Tesis de Doctorado.

BROWN, M., 1998 - Can Culture Be Copyrighted? Current Anthropology, 19 (2): 193-222.

BROWN, M., 2003a - Who Owns Native Culture ?, 315 pp.; Cambridge-London: Harvard University Press

BROWN, M., 2003b - Safeguarding the Intangible. Cultural Commons; New York < http:// www.culturalpolicy.org/commons/comment-print.cfm? ID $=12>$.

CARNEIRO DA CUNHA, M. (ed.), 1992 - História dos Indios no Brasil, 608 pp.; Sâo Paulo: Companhia Das Letras, SMC-FAPESP.

CHAPARRO ORTíz de CEVALLOS, A., 2008 - Los yagua en el contexto del turismo étnico. La construcción de la cultura para el consumo en el caso de Nuevo Perú. Anthropologica, XXVI (26): 113-142.

CHAUMEIL, J.-P., 1984 - Entre el Zoo y la esclavitud: los yagua del Oriente peruano en su situación actual, 82 pp.; Copenhague: Documento IWGIA 3.

CHAUMEIL, J.-P., 2005 - Sur la notion d'esprits-maîtres et l'agentivité en Amazonie amérindienne. Ponencia presentada en el seminario «agentivité» del Centro EREA del Laboratoire d'Ethnologie et de Sociologie Comparative, CNRS-Université París Ouest-Nanterre La Défense (A. Monod \& V. Vapnarsky, org.). 
DENIS, F., 1850 - Une fête brésilienne célébrée à Rouen en 1550, 104 pp.; París: J. Techner.

DERLON, B. \& JEUDY-BALLINI, M., 2008 - La passion de l'art primitif. Enquête sur les collectionneurs, 322 pp.; París: Gallimard.

DE VIENNE, E. \& ALLARD, O., 2005 - Pour une poignée de dollars ? Transmission et patrimonialisation de la culture chez les Trumai du Brésil central. Cahiers des Amériques Latines, 48-49 (1-2): 126-145.

DZIUBINSKA, M., 2008 - Le commerce du chamanisme parmi les Shipibo-Conibo dans le contexte du tourisme mystique (Amazonie péruvienne), 116 pp.; París: Memoria de Maestría de l'École Pratique des Hautes Études en Sciences Sociales.

FAUSTO, C., 2008 - Donos demais: maestria e domínio na Amazônia. Mana, 14 (2): 329-366.

FIORINI, M. \& BALL, C., 2006 - Le commerce de la culture, la médecine rituelle et le Coca-Cola. Gradhiva, 4: 96-113.

GALLEGO, L. M., 2004 - El tejido de la vida: acercamiento etnográfico al tejido de chambira de la comunidad Yagua de La Libertad; Universidad de Antioquia. Tesis de pregrado.

GALLOIS, D., 2006 - Patrimônio cultural Imaterial e povos indígenas, 92 pp.; Sâo Paulo: lepé.

GORDON, C., 2009 - Economie sauvage : consommation, marchandise et monnaie chez les Xikrin (Kayapó) de l'Amazonie brésilienne; París: Maison des Sciences de I'Homme. Ponencia presentada al Séminaire d'Anthropologie Américaniste.

GRISALES, G., 2008 - Sin maldad y colmado de frutales. El progreso, la integración y la globalización de una frontera amazónica colombiana, peruana, brasilera y antiguamente quiteña, 352 pp.; Quito: Ediciones Abya-Yala.

GUTJAHR, E., 2008 - Entre tradições orais e registros da oralidade indígena; São Paulo: Universidade de São Paulo. Tesis de mestrado.

HOTTIN, C. (ed.), 2008 - Dossier Le Patrimoine Culturel Immatériel. Culture \& Recherche, 116-117: 10-54.

HUGH-JONES, S., 2009 - Patrimonialisation : entre image et écrit; París: Institut des Hautes Études de l'Amérique Latine. Conferencia presentada al Seminario de ERSIPAL.

JACKSON, J., 1995a - Culture, genuine and spurious: the politics of Indianness in the Vaupès, Colombia. American Ethnologist, 22 (1): 3-27.

JACKSON, J., 1995b - Preserving Indian Culture: Shaman Schools and Ethno-Education in the Vaupés, Colombia. Cultural Anthropology, 10 (3): 302-329.

KURIN, R., 2003 - Tangible Progress. A response to 'Safeguarding the intangible' by M. Brown. Cultural Commons; New York < http://www.culturalcommons.org/kurin.htm>.

MÜNZEL, M., 2000-2001 - Lo efímero en las artes de los indígenas sudamericanos. Bulletin de la Société Suisse des Américanistes, 64-65: 157-160.

OCHOA, G., 2008a - El turismo: ¿una nueva bonanza en la Amazonía? In: Fronteras de la globalización: localidad, biodiversidad y comercio en la Amazonía (C. Zárate \& C. Ahumada, eds.): 43-70; Bogotá: Observatorio Andino.

OCHOA, G. (ed.), 2008b - Turismo en la Amazonía. Entre el desarrollo convencional y las alternativas ambientales amigables, 231 pp.; Bogotá: Universidad Nacional de Colombia Sede Amazonía, Instituto IMANI.

OCHOA, G., 2008c - Turismo y Cadenas Globales de Mercancías en la Amazonía. In: Turismo en la Amazonía (G. Ochoa, ed.): 9-21; Bogotá: Universidad Nacional de Colombia Sede Amazonía, Instituto IMANI.

OCHOA, G., BUILES, D., CARROLL, I., CARVAJAL, J. \& GALLEGO, L., 2008 - Leticia: toda la Amazonía en un solo lugar. Plan sectorial de turismo para Leticia y el Trapecio Amazónico colombiano. In: Turismo en la Amazonía (G. Ochoa, ed.): 171-212; Bogotá: Universidad Nacional de Colombia Sede Amazonía, Instituto IMANI. 
PASTOR ALFONSO, M. J., 2007 - Una apuesta por la sostenibilidad y la proyección de la identidad cultural. Turismo alternativo en pequeñas comunidades latinoamericanas. Anales del Museo de América, XV: 207-216.

PERRONE-MOISES, B., 2008 - L'alliance normando-tupi au XVI siècle: la célébration de Rouen. Journal de la Société des Américanistes, 94 (1): 45-64.

RODRÍGUEZ, I. \& APONTE, J., 2008 - Frontera, turismo y modernidad en el relato de la globalidad. Algunos reflejos en la Amazonía. In: Fronteras de la globalización (C. Zárate \& C. Ahumada, eds.): 127-149; Bogotá: Observatorio Andino.

SEILER-BALDINGER, A.-M., 1988 - Tourism in the Upper Amazon and its Effects on the Indigenous Population. In: Tourism: Manufacturing the Exotic (P. Rossel, ed.): 177-193; Copenhague: IWGIA Document 61.

STRONZA, A., 2001 - Anthropology of Tourism: Forging New Ground for Ecotourism and Other Alternatives. Annual Review of Anthropology, 30: 261-283.

TAYLOR, G., 1996 - La tradición oral quechua de Chachapoyas, 124 pp.; Lima: IFEA, ATOQ.

TAYLOR, L., 2008 - They may say tourist, may say truly painting: aesthetic evaluation and meaning of bark paintings in western Arnhem Land, northern Australia. Journal of the Royal Anthropological Institute, 14: 865-885.

TRUFFIN, B., 2006 - Droits autochtones amazoniens et droit officiel équatorien : une opposition culturelle? Le cas des Runa et des Shiwiars. Civilisations, LV (1-2): 143-162. 